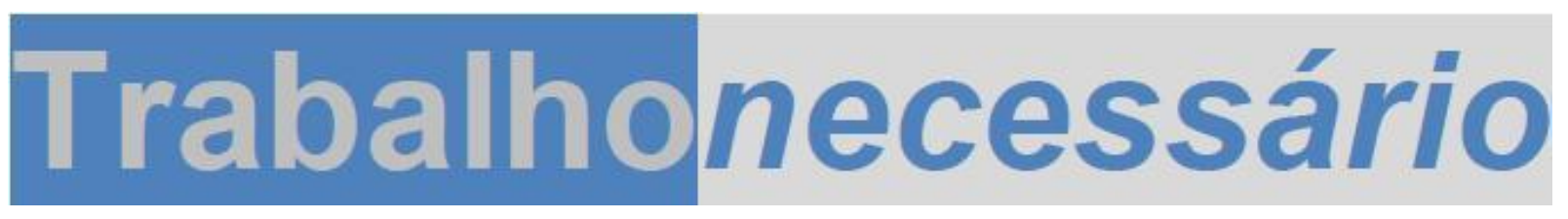

\author{
Issn: 1808 - 799X
}

ano 12, no $18-2014$

\title{
O LEGADO DE THOMPSON PARA A PESQUISA SOBRE POLÍTICAS PÚBLICAS
}

Eveline Algebaile ${ }^{1}$

\section{Resumo}

O artigo apresenta formulações de Thompson entendidas como fundamentais para estudos sobre políticas públicas que não as circunscrevam às suas configurações oficiais e a suas aparentes cristalizações. Reporta-se especialmente a discussões do autor que, ao enfatizarem as condições objetivas e subjetivas reais nas quais se dão as relações constitutivas da classe e da experiência de classe, evidenciam a necessidade de se considerar, na análise das formas institucionalizadas, a heterogeneidade, as variações e as instabilidades que presidem e põem em permanente movimento os processos de institucionalização. Argumenta que a ênfase dada por Thompson às tensões, contradições, fraturas e oposições atuantes no curso da história permite evidenciar o presente e o futuro como realidades em produção, favorecendo formas de compreensão crítica capazes de reconhecer, nos processos em curso de discussão, formulação, implementação e acompanhamento de políticas públicas, as condições reais de disputa contra-hegemônica de seus sentidos.

Palavras-chave: E. P. Thompson; políticas públicas; processo histórico.

\footnotetext{
${ }_{1}^{1}$ Professora Adjunta da Faculdade de Formação de Professores (FFP) da Universidade do Estado do Rio de Janeiro (UERJ). Professora dos Programas de Pós-Graduação em Educação da FFP e em Políticas Públicas e Formação Humana (PPFH). Procientista UERJ e Bolsista do Programa JCNE/Faperj. ealgebaile@gmail.com
} 


\title{
Trabalhonecessário
}

Issn: 1808 - 799X

ano 12, no $18-2014$

\section{THOMPSON'S LEGACY TO RESEARCH ON PUBLIC POLICY}

\begin{abstract}
The paper presents Thompson's formulations understood as fundamental to studies on public policy that does not restrict them to official conformation and its apparent crystallizations. It refers especially to the author's discussions that demonstrate the need to consider - within institutionalized structures' analysis - the heterogeneity, variations and instabilities that manage and put institutionalization processes in continual motion by emphasizing real objective and subjective conditions in which class constitutive relations and experiences happen. It reasons that Thompson's emphasis on tensions, contradictions, fractures and oppositions operated in the course of history allows to make present and future as realities in production clear, sustaining forms of critical comprehension capable of recognizing the real conditions of counter-hegemonic dispute of their meanings through the ongoing processes of discussion, formulation, implementation and evaluation of public policies.
\end{abstract}

Keywords: E. P. Thompson; public policy, historical process

\section{Introdução}

Minha primeira leitura de um texto do historiador Edward Palmer Thompson, no início dos anos 1990, foi oportunamente desconcertante.

Naquele momento, minha atuação profissional e meus estudos já estavam claramente situados no campo das políticas públicas e o esforço para compreender sua configuração, no momento mesmo em que elas estavam sendo constituídas e modificadas, fazia com que eu me sentisse imersa num tempo presente cujo dinamismo acabava sendo percebido como uma "natureza" contrastante com o "andamento da história". O estudo do passado podia se ancorar nas sedimentações, na visibilidade das coisas que haviam resistido aos revezes do tempo e se tornado realidades sólidas. O presente, ao contrário, aparecia como intensa ebulição, dificultando a identificação daquilo que iria constituir os supostos sedimentos da história. Nesse quadro de compreensão, o

TrabalhoNecessário - www.uff.br/trabalhonecessario; Ano 12, №18/2014. 


\section{Trabalhonecessário}

Issn: 1808 - 799X

ano 12, no $18-2014$

estudo de políticas públicas aparecia como uma empreitada que precisava se concentrar na apreensão de resultados palpáveis, e estes pareciam sempre mais visíveis nas decisões tomadas e nas normas que conferiam duração e vigência a essas decisões.

Assim, ao ler "A formação da classe operária inglesa", estranhei aquele historiador que, ao entrar na história segundo um modo de estar típico de quem vive o presente, parecia apreender e revelar, de forma inédita para mim, as mais variadas formas de combinações e derivações possíveis entre "ebulição" e "sedimentação", recusando-se a ler "a história à luz de preocupações posteriores" (2004, p. 13) e, por conseguinte, tal como eu leria mais tarde em "Costumes em Comum" (1998), a "distrair [sua] atenção das contradições sociais e culturais, das fraturas e oposições existentes dentro do conjunto." (1998, p. 17). Na perspectiva por ele adotada, as decisões tomadas e as normas instituídas não se sobrepunham à atuação daqueles que, apesar de figurarem como perdedores, "contribuíram com esforços conscientes, no fazer-se da história". Causas perdidas em um contexto poderiam ser ganhas em outro. Por isto, e por muitos outros motivos, tínhamos muito a aprender com as aspirações e tentativas que, apesar de estranhas aos nossos modos de ser, pensar e agir, são válidas nos termos de uma experiência que ignoramos (2004, p. 13).

Desde então, li e usei os textos de Thompson muito menos do que eu gostaria e deveria, mas talvez o bastante para saber que estava diante de formulações fundamentais para uma compreensão das políticas públicas em produção, capaz de não reduzi-las aos aspectos mais diretamente validados pelo critério da oficialidade.

Este texto está circunscrito à apresentação e discussão de algumas formulações do autor relacionadas a esse quadro de problematização. Nele, serão apresentados alguns pontos das formulações de Thompson que, de meu ponto de vista, municiam-nos a olhar as políticas públicas a partir das "contradições, fraturas e oposições" que constituem o presente e o futuro como 


\section{Trabalhonecessário}

Issn: 1808 - 799X

ano 12, no $18-2014$

realidades em disputa, por mais que a forma oficial lograda por cada política pareça indicar, a toda hora, que a história acabou.

As principais referências do texto são discussões do autor que, ao enfatizarem as condições subjetivas e objetivas reais nas quais se dão as relações constitutivas da classe e da experiência de classe, evidenciam a necessidade de se considerar, na análise das formas institucionalizadas, a heterogeneidade, as variações e as instabilidades que precedem, constituem e põem em permanente movimento os processos de institucionalização.

\section{Um ponto de partida fundamental para o estudo de políticas públicas}

Os estudos sobre políticas públicas não podem prescindir de uma clara caracterização da sua configuração formal nos contextos estudados. Por mais esquemático que possa parecer, público-alvo, escopo, cobertura, base institucional, matriz organizacional, dentre outros, são itens de informação que precisam ser definidos em qualquer investigação sobre tais políticas. Dependendo da perspectiva adotada, no entanto, as informações referentes aos itens acima indicados podem ter pesos e sentidos completamente distintos.

Em algumas perspectivas, as definições formais encontradas nos documentos normativos, programáticos e instrucionais, que estabelecem, regulamentam e instruem a realização de cada política, são uma espécie de ponto de chegada da investigação.

Em outras, a identificação das definições normativas estará presente em diferentes momentos de um conjunto complexo de indagações que serão formuladas e reorientadas no curso da investigação.

A que âmbitos da vida se refere tal política? A quais segmentos sociais se destina? Por meio de que processos ela foi formulada e é acompanhada? Que forças, e com que peso, participam desses processos? Quais são as diretrizes de cobertura territorial e populacional da política investigada? Qual a correlação entre tais diretrizes e a cobertura real? Qual o espectro de ações previsto? Quais os procedimentos definidos para sua implementação? Quais as bases financeiras e

TrabalhoNecessário - www.uff.br/trabalhonecessario; Ano 12, № 18/2014. 


\section{Trabalhonecessário}

Issn: 1808 - 799X

ano 12, no $18-2014$

institucionais para sua realização? Em que seu desenho atual difere dos desenhos precedentes? O que sinalizam essas diferenças? Em quais noções de direitos e deveres se assenta em cada contexto estudado? Como foram constituídos historicamente os corpos profissionais que atuam na sua realização? O que isto tem a ver com as formas presentes de realização da política estudada? Quais os nexos entre os diferentes aspectos de sua configuração e a correlação de forças presente nos diferentes momentos de sua formulação e acompanhamento?

A opção de investigar as políticas públicas a partir de referências da ciência política e, em particular, a partir de formulações de autores como Karl Marx e Antonio Gramsci, levou-me a concentrar a atenção nos processos por meio dos quais vão se definindo as condições objetivas e subjetivas nas quais (e a partir das quais) cada política se organiza.

Um dos objetivos, neste caso, é ampliar o lastro de informações que nos permitem cotejar o desenho formal assumido por uma política no presente, ou o quadro geral de sua disputa, com a histórica política, normativa e institucional precedente. Sem esse cotejo, seria impossível avaliar, com um mínimo de ponderação, certos sentidos da política no próprio presente, como os relacionados a seu caráter de continuidade ou ruptura; conservação ou renovação; restauração ou transformação. Seria também impossível proceder a uma análise adequada da correlação de forças implicada na sua produção, já que, como mostra Gramsci (2000), tal análise depende não apenas da devida identificação das forças sociais e políticas atuantes em cada contexto, mas também, necessariamente, da compreensão das modificações de peso e de composição que acabam por influir nas posições relativas assumidas por cada força em cada contexto.

Os estudos de Thompson dão um lastro extraordinário à consideração dos aspectos acima indicados, não apenas ao municiar o estudo do passado de uma política, mas especialmente ao evidenciar o que precisa ser levado em conta 


\section{Trabalhonecessário}

Issn: 1808 - 799X

ano 12, no $18-2014$

quando nos dispomos a apreender a realidade a partir das condições reais (institucionais, políticas, sociais) de sua movimentação no presente.

As discussões sobre a formação social e cultural como algo que só se define no "fazer-se da história" tem muito a nos indicar nesse sentido.

\section{Pelos olhos de Thompson}

Ao concentrar sua atenção nas movimentações da história em suas variadas implicações com a formação social e cultural, Thompson alertou para a necessidade de não tratarmos tais formações por suas aparentes cristalizações.

$\mathrm{Na}$ análise da formação da classe operária inglesa, por exemplo, o autor adverte que, sendo a classe, antes de tudo, uma relação histórica - e, portanto, "sempre encarnada em pessoas e contextos reais" (2004, p.10) -, sua compreensão é inevitavelmente dependente do estudo dessa relação, cujo caráter obrigatoriamente fluido escapará à análise se "tentarmos imobilizá-la em dado momento e dissecar sua estrutura" (2004, p.10). As formas institucionais alcançadas em diferentes momentos da história de uma formação social não são estruturas estáticas, mas formas vivas e em movimento que, tal como as tradições e os sistemas de valores, encarnam as relações que os homens contraem e as formas de consciência que são elaboradas no curso dessas relações.

Há muito o que destacar nessa formulação com vistas à expectativa, acima apresentada, de considerar as políticas públicas no curso de sua produção.

Um primeiro aspecto a notar é que a ênfase dada por Thompson à fluidez da relação histórica não expressa uma concepção de história como uma sucessão caótica de acontecimentos, sem nexos de sentido e sem regularidades passíveis de compreensão. Para o autor, é possível e necessário que o estudo do curso da história identifique lógicas, regularidades e padrões. Porém, não para revelá-los como supostas leis, ou seja, como formas estáticas e coesas que existiriam por si e presidiriam os acontecimentos; mas para entendê-los como

TrabalhoNecessário - www.uff.br/trabalhonecessario; Ano 12, №18/2014. 


\section{Trabalhonecessário}

Issn: 1808 - 799X

ano 12, no $18-2014$

resultado de relações dinâmicas, entre práticas, culturas, ideias e forças heterogêneas que, no decorrer do tempo, mostram-se implicadas tanto com diferenciações, dissensos e confrontos, quanto com aproximações, consensos e agregações.

Não é fortuita, portanto, a ênfase dada por Thompson à heterogeneidade e à diferenciação (societária, profissional, ocupacional, religiosa...) presentes na constituição de uma força social e política (a classe operária inglesa) cujo reconhecimento (político, mas também analítico) só se daria, efetivamente, a partir do momento em que ela passa a ser percebida na cena pública por seus elementos de consenso, coesão e organização.

Contrariando a tendência a caracterizar uma força política pela configuração institucional por ela apresentada no momento de sua mais elaborada organização, Thompson se dedica à apreensão da variedade e da variabilidade dos aspectos que constituem o terreno complexo da formação histórica da força em questão.

Um aspecto importante de se observar, neste caso, é como Thompson "delimita" o âmbito das relações e experiências constitutivas da classe. Como não se trata de flagrar algo pré-definido, cuja manifestação se daria independentemente da ação dos homens enquanto fazem sua própria história; como, ao contrário, trata-se de rastrear uma formação histórica posta em movimento por uma multiplicidade de processos que obrigatoriamente antecedem, constituem e atravessam os momentos de sua mais clara institucionalização, as delimitações temporais deixam de acompanhar os marcos da história oficial e passam a perseguir as indicações de emergência e duração de práticas e relações que se fazem presentes nos múltiplos processos atuantes no curso dessa formação.

Isto tem importantes repercussões em termos de outras delimitações. No que diz respeito à definição dos âmbitos da vida social a partir de onde se constituem essas práticas e relações, pode-se observar, primeiramente, a atenção do autor a uma impressionante variedade de instâncias institucionais em

TrabalhoNecessário - www.uff.br/trabalhonecessario; Ano 12, № 18/2014. 


\section{Trabalhonecessário}

Issn: 1808 - 799X

ano 12, no $18-2014$

diferentes momentos e condições de organização. Igrejas, clubes literários, sociedades de correspondência e outros tipos de associações somam-se à identificação de uma multiplicidade de espaços de realização de atividades laborais relacionadas a um variado espectro de ramos produtivos.

A ideia central é que as práticas e relações presentes ao longo do complexo processo de organização da classe não têm origem circunscrita aos espaços de trabalho. Podem originar-se a partir de vários âmbitos de participação na vida social, combinando-se de diferentes modos e conforme as possibilidades de cada contexto.

As próprias relações mais diretamente vinculadas às atividades laborais não são analisadas pelo autor apenas em função das características estritamente relativas às suas funções produtivas. Thompson leva em conta, por exemplo, as variadas formas de presença das diversas atividades no território e as possibilidades de relação entre distintos segmentos profissionais que disto resulta.

A maior ou menor presença de uma atividade produtiva em uma área, a proximidade de uma Igreja, de um clube literário ou de outra forma de associação podem alterar o escopo das relações sociais e, por conseguinte, as possibilidades e sentidos da experiência nelas constituída. As hierarquias internas, os critérios de classificação e prestígio, bem como as lógicas de organização de cada ramo de atividade são também aspectos levados em conta na tentativa de discernir as condições em que se dão as relações entre os distintos segmentos sociais e suas possibilidades de adesões, dissenções ou agregações futuras.

As delimitações não se dão, portanto, na forma de demarcação formal de períodos ou de seleção formal das atividades que comporão o escopo da investigação. É a temporalidade dos processos e suas ramificações que vão indicando ao pesquisador por onde seguir para apreender os "pontos de junção" (1981, p. 189; 2004, p. 19), ou os "bloqueios", "escapes", "adesões tensas" (2004, p.44), ou, ainda, os movimentos por meio dos quais se passa das formas mais elementares de resistência para estratégias ancoradas no próprio código da ação

TrabalhoNecessário - www.uff.br/trabalhonecessario; Ano 12, № 18/2014. 


\section{Trabalhonecessário}

Issn: 1808 - 799X

ano 12, no $18-2014$

dominante $^{2}$, dentre outros traços que ajudem a esclarecer o surgimento de novas formas de organização.

É importante observar, a esse respeito, que a reiteração de certas formas organizacionais não implica, para Thompson, reiteração de conteúdo e de significado. Uma mesma forma de ação (um motim, uma greve, a constituição de um comitê de acompanhamento eleitoral ou a organização de um controle da contabilidade) pode ser portadora de novos conteúdos, se observarmos não a forma em si, mas o tipo de intervenção que opera em cada contexto. Conservação e mudança, portanto, não aparecem como atributos estáticos e binariamente opostos na ação política, mas como resultados das formas como diferentes modos de agir podem ser acionados no curso da ação. Diferentes combinações entre as várias formas de ação podem implicar significados distintos.

É possível observar, com as indicações acima apresentadas, que a ênfase de Thompson na heterogeneidade e na diferenciação social não é posta a serviço da apresentação de um estado passado que seria caracterizado pela desagregação e que, em algum momento, teria sido superado por formas coesas evidentes em momentos mais sólidos de sua organização. Para o autor, a história da classe não é uma história de aspectos comuns previamente existentes que, descobertos, fomentariam um processo de organização. Heterogeneidade e diferenciação são o que constitui o terreno real de referências a partir das quais se dá a elaboração (histórica, cultural, política) de formas possíveis de percepção coletiva capazes de levarem os grupos a se reposicionarem, interna e externamente, em termos de seu alinhamento, de seu antagonismo ou de sua agregação.

Nessa perspectiva, homogeneidade e heterogeneidade também não são compreendidas como configurações de caráter oposto. Na verdade, aparecem como condições diversas (não necessariamente opostas) de produção de formas

\footnotetext{
${ }^{2}$ Como, por exemplo, nos embates em torno das investidas dos empregadores sobre os hábitos e o tempo de trabalho do povo, nos séculos XVIII e XIX, na Inglaterra (THOMPSON, 1998, 293-294).
}

TrabalhoNecessário - www.uff.br/trabalhonecessario; Ano 12, № 18/2014. 


\title{
Trabalhonecessário
}

Issn: 1808 - 799X

ano 12, no $18-2014$

de ser, pensar e agir, de produção de formas de organização, de difusão e composição de ideias. E não são compreendidas segundo uma relação valorativa hierárquica linear, na qual a homogeneidade seria sempre concebida como um estágio superior, alcançado por meio da superação da heterogeneidade.

Formas heterogêneas de ação configuradas num contexto conservador, por exemplo, podem ser ressignificadas no curso da história e se combinarem segundo complexas composições, tornando-se importante instrumento de estruturação de ações orientadas para a transgressão de uma ordem instituída.

Nessa perspectiva, noções como as de cultura ou resistência podem se reportar a práticas ou a configurações históricas muito variadas, como é possível perceber na passagem abaixo transcrita:

\begin{abstract}
Eu hesitaria antes de descrever essa cultura como uma cultura de classe, no sentido em que se pode falar de uma cultura da classe trabalhadora no século XIX, na qual as crianças eram socializadas num sistema de valores com notações de classe distintas. Mas não se pode compreender essa cultura, nos termos da experiência, na sua resistência à homilia religiosa, na sua zombaria picaresca das prudentes virtudes burguesas, no seu pronto recurso à desordem e nas suas atitudes irônicas para com a lei, a menos que se empregue o conceito dos antagonismos, ajustes e (às vezes) reconciliações dialéticas de classe. (1998, p. 69)
\end{abstract}

Essas indicações alertam para o fato de que a análise da história não pode se circunscrever ao acompanhamento dos acontecimentos que, aparentemente, orientam-se num mesmo sentido. É preciso atenção à variedade e à variação das ações no tempo, seus entrecruzamentos e pontos de junção, de modo a percebermos a "maneira pela qual os diferentes fenômenos agiram uns sobre os outros" (1981, p.49). Tanto da homogeneidade quanto da heterogeneidade podem vir fermentos diversos para o conflito e para a agregação. E isto tem tudo a ver com os estudos de políticas públicas que indaguem sobre as condições reais de sua disputa a favor da garantia do exercício de direitos sociais e a favor de novos projetos de sociedade. 


\section{Trabalhonecessário}

Issn: 1808 - 799X

ano 12, no $18-2014$

\section{A análise das políticas no presente: o que levar em conta?}

Do conjunto de questões acima brevemente apresentado, podemos extrair importantes indicações para pensar as políticas públicas no presente, na perspectiva de indagar suas condições de disputa e produção.

Uma primeira indicação diz respeito exatamente à importância de não circunscrevermos a análise do presente aos sujeitos, práticas e ações que, por sua posição hegemônica no contexto considerado, tendem a ser diretamente relacionados ao desenho oficial logrado pela política investigada.

Isto não apenas nos compromete com a consideração de uma multiplicidade de sujeitos, práticas e ações. Alerta-nos para a necessidade de conferirmos destaque aos sujeitos e práticas que, apesar de apresentarem um peso considerado irrelevante nas correlações de forças implicadas na disputa dos sentidos de uma política no passado ou no presente, ocupam posição central na história de uma política por referenciá-la.

Como diz Thompson, "Não podemos ter amor sem amantes, nem submissão sem senhores rurais e camponeses" (2004, p. 10). Uma "política pública" é, antes de tudo, um mecanismo regulador de relações e não temos como entender as possibilidades de sua disputa se não levamos em conta quais relações se quer, com ela, regular; e, portanto, quais são os sujeitos, práticas e ações que, mesmo independentemente de sua vontade, participam dessas relações.

Isto quer dizer que, ao analisarmos uma política de saúde ou de educação, por exemplo, não faz sentido não levar em conta como pensam, agem e lutam aqueles que, mesmo ocupando as posições mais subordinadas nas decisões sobre o desenho da política investigadas, são mais centralmente atingidos por suas ações ou suas omissões.

Não é fácil levar em conta como pensam, agem e lutam sujeitos subordinados numa relação. Requer, como insistiu Valla (2011), exercícios de compreensão que nos ajudem a não apreender os "perdedores" a partir de

TrabalhoNecessário - www.uff.br/trabalhonecessario; Ano 12, № 18/2014. 


\section{Trabalhonecessário}

Issn: 1808 - 799X

ano 12, no $18-2014$

comparações com os modos de ser, agir e pensar que achamos mais adequados para enfrentar uma situação; e a reconhecer, como insistiu Thompson (2004, p. 13), seus esforços e suas aspirações, entendendo o quanto são "válidas nos termos das suas próprias experiências".

O alerta de Thompson a respeito da consideração das condições subjetivas e objetivas a partir das quais se dá uma formação social e cultural é, do ponto de vista aqui adotado, não apenas válido, mas científica e politicamente necessário para a análise de políticas e instituições, por nos possibilitar entendê-las como produções humanas, sociais, e só por isso passíveis de serem disputadas.

Essas condições, no caso das políticas públicas, envolvem a história das noções de direitos, de suas formas de declaração, a história normativa e institucional das políticas a eles referidas, mas também a história política, relativa às condições de formação e atuação das forças que se põem em relação no curso de elaboração e realização das políticas investigadas. $E$ isto implica 0 conhecimento tanto das forças hegemônicas quanto das demais forças, cujas possibilidades de agregação no presente só poderão ser adequadamente compreendidas se, como já dito acima, não distrairmos nossa "atenção das contradições sociais e culturais, das fraturas e oposições existentes dentro do conjunto" (THOMPSON, 1998, p. 17).

É preciso, para isto, recusar concepções de "consciência" e "antagonismo" ancoradas em fórmulas idealizadas que tornam invisíveis e incompreensíveis em seus limites e em suas potências - as formas históricas reais de pensar e agir, numa relação de disputa.

Como mostra Thompson, as formas hegemônicas podem definir "os limites dentro dos quais [uma] cultura [...] tem liberdade de atuar e crescer". Mas essa hegemonia, inúmeras vezes, não pode determinar por completo "o caráter dessa cultura [...]" (1998, p. 19). Isto nos ajuda a perceber que, no estudo das relações que vão definindo o perfil de uma política, para além das formas de controle e das formas clássicas de confronto, é fundamental também considerar o que escapa às formas hegemônicas: as reservas de liberdade, as formas defensivas, as

TrabalhoNecessário - www.uff.br/trabalhonecessario; Ano 12, № 18/2014. 


\title{
Trabalhonecessário
}

Issn: 1808 - 799X

ano 12, no $18-2014$

mutações de costumes podem evidenciar formas variadas de resistência capazes de portarem "respostas práticas" de grande importância no curso de disputas que ainda se dão em situações de grande assimetria entre as forças em relação.

A consciência capaz de converter essas variadas formas de resistência em projetos que antagonizem com as formas hegemônicas não pode ser "adquirida". Ela só se produz no interior dessas experiências e será sempre correspondente às formas históricas como essas experiências são vividas e "tratadas em termos culturais" (THOMPSON, 2004, p. 10). Não levá-las em conta no estudo de políticas é o mesmo que contar uma "história de amor sem amantes": elas aparecerão como realidades dadas, que, ao não poderem ser compreendidas nas condições concretas em que se dão suas formas reais de disputa, terão limitadas as próprias possibilidades de serem disputadas.

\section{Considerações finais}

Em um texto publicado em 2003, relativo às contribuições de Thompson para a pesquisa em educação, Maria Célia Marcondes de Moraes e Ricardo Müller argumentam que

\begin{abstract}
Thompson interessa porque, como assinala Inglis (1982, p. 199), ele nos ofereceu "um novo passado para viver", transformando "a memória social, de modo que as pessoas puderam definir novas perspectivas, na medida em que passaram a compreender de outro modo a formação do presente." Ou então, como aponta Müller (2002, p. 14), porque ele exerceu oposição apaixonada à crescente desumanização das relações sociais, marca de sua contribuição ao que ele considerava o processo de luta popular por uma sociedade democrática. O materialismo histórico foi por ele reafirmado em seu caráter de teoria da emancipação humana, de constante renovação dos valores de uma cultura de dissidência." (MORAES e MULLER, 2003, p. 332)
\end{abstract}

De fato, Thompson é daqueles pensadores que acionam em nós, a um mesmo tempo, novas condições de compreensão e novas expectativas de produção coletiva da vontade.

A ênfase dada por Thompson às tensões e contradições atuantes no curso da história permite evidenciar o presente e o futuro como realidades em produção, desalojando-nos das posições cômodas que tratam os mais diversos âmbitos da

TrabalhoNecessário - www.uff.br/trabalhonecessario; Ano 12, № 18/2014. 


\section{Trabalhonecessário}

Issn: 1808 - 799X

ano 12, no $18-2014$

vida social como realidade fechada, em relação a qual só nos caberia constatar, seja para aderir, seja para rejeitar.

No que diz respeito ao estudo sobre políticas públicas, suas formulações, ao deslocarem nosso esforço de compreensão das configurações formais das políticas investigadas para as instabilidades que precedem e atravessam sua produção, favorecem formas de compreensão crítica capazes de possibilitar o reconhecimento das condições objetivas e subjetivas reais de disputa contrahegemônica de seus sentidos nos processos de sua discussão, formulação, implementação e acompanhamento.

Esta é uma destinação da pesquisa que não pode ser negligenciada por aqueles que, coerentemente com o pensamento político de Marx, sabem que de nada vale "conhecer a realidade", se não for com a pretensão de transformá-la.

Em tempos como os atuais, em que a reconfiguração das políticas públicas referidas a direitos sociais duramente disputados - educação, saúde, habitação, assistência, trabalho.... - parece reduzir as possibilidades de efetiva participação social no seu desenho e nas suas formas de realização, a leitura de Thompson, além de nos fornecer instrumentos de compreensão dos fenômenos em suas movimentações e das formas como uns agem sobre os outros, municia-nos a valorizar política e analiticamente a atuação daqueles cuja participação nas políticas que Ihes são dirigidas, faz-se, muitas vezes, a partir de lugares previamente definidos como de perdedores.

Em uma sociedade na qual as formas mais elaboradas de informação pública coexistem com o (e se alimentam do) sistemático silenciamento daqueles que sofrem os lados mais erodidos das políticas sociais ou a sua ausência completa, é fundamental entender que sabemos pouco ou nada dessas políticas se não conhecemos a experiência desses "perdedores", se nada sabemos de suas aspirações, se acreditamos que elas sequer existem e se somos cegos à possibilidade de que elas sejam "válidas nos termos de sua própria experiência". 


\section{Trabalhonecessário}

Issn: 1808 - 799X

ano 12, no $18-2014$

\section{Referências}

GRAMSCI, Antonio. Cadernos do cárcere. Volume 3. Maquiavel. Notas sobre o Estado e a política. Rio de Janeiro: Civilização Brasileira, 2000.

MORAES, Maria Célia Marcondes de; e MÜLLER, Ricardo Gaspar. História e experiência: contribuições de E. P. Thompson à pesquisa em educação. Perspectiva, Florianópolis, v. 21, n. 02, p. 329-349, jul./dez. 2003.

THOMPSON, Edward Palmer. A formação da classe operária inglesa I. A árvore da liberdade. 4를. Edo de Janeiro, Paz e Terra, 2004.

A formação da classe operária inglesa II. A maldição de Adão. $4^{a}$ Ed.Rio de Janeiro, Paz e Terra, 2002.

A formação da classe operária inglesa III. A força dos trabalhadores. $3^{\text {a }}$ Ed. Rio de Janeiro, Paz e Terra, 2002.

Costumes em comum. Estudos sobre a cultura popular tradicional. São Paulo, Companhia das Letras, 1998.

A miséria da teoria. Rio de Janeiro, Zahar, 1981.

VALLA, Victor Vincent. Procurando compreender a fala das classes populares. In: VALLA, V. V.; ALGEBAILE, E.; GUIMARÃES, M.B. Classes populares no Brasil: exercícios de compreensão. Rio de Janeiro, ENSP/Fiocruz, 2011, p. 91-103.

Recebido em maio de 2014.

Aprovado em junho de 2014. 